\title{
Microsatellite-Based Genetic Structure and Differentiation of Goldfish (Carassius auratus) with Sarcoma
}

\author{
Zaizhong Chen', Caixia Hu', Lei Wang1, Guiqin Chen², Jun Wang1, Hance Huang', \\ Anyuan He ${ }^{1}$, Chenghui Wang1, Weihua Zhao ${ }^{2}$ \\ ${ }^{1}$ College of Fisheries and Life Sciences, Shanghai Ocean University, Shanghai, China \\ ${ }^{2}$ Shanghai Pudong Ornamental Fish Center, Shanghai, China \\ Email: chenzz@shou.edu.cn, wangch@shou.edu.cn
}

Received 29 October 2014; accepted 20 November 2014; published 13 January 2015

Copyright (C) 2015 by authors and Scientific Research Publishing Inc.

This work is licensed under the Creative Commons Attribution International License (CC BY). http://creativecommons.org/licenses/by/4.0/

c) (i) Open Access

\section{Abstract}

Ten microsatellite loci were used for analyzing six populations of goldfish (Carassius auratus) with sarcoma. It showed that there was the highest genetic diversity among the white oranda with red cap (RC) population, and the lowest among the white tigerhead (WT) population. However, the outcross existed among every population. There was huge genetic differentiation between WT and the other four populations. The average observed heterozygosity $\left(H_{0}\right)$ among populations ranged from 0.3571 to 0.7381 . And significant genetic difference $\left(F_{\mathrm{CT}}=0.1891, P=0.0186\right)$ appeared among goldfish varieties which can be classified into three groups (RT, WT; RL, BL, YC; RC). The software Principal Coordinate Analysis (PCA) and STRUCTURE showed that significant genetic differences were revealed between RC population of goldfish and other five populations.

\section{Keywords}

Carassius auratus, Microsatellite, Genetic Diversity

\section{Introduction}

The goldfish is a very important ornamental fish in China, as well as a very popular pet around the world due to its variety of color patterns and morphological characteristics. It is speculated that this species was derived from wild crucian carp (C. auratus) under the combined forces of natural selection and domestication pressures, especially artificial breeding practice [1]. As consequence, goldfish has been developed in plenty of varieties or strains, such as the dragon-eye, moor, and ryukin strains [2] [3]. In human-mediated domestication process, the 
breeders have paid more attention to the goldfish variation and hoped to develop the goldfish with high ornamental value and to keep their substantial variation [4]. According to dorsal fin, two taxonomies of goldfish can be clearly defined: one consists of dorsal fins goldfish (such as shubunkin and kurodemekin) and another is nondorsal fins goldfish (such as ranchu, chotengan and chinese ranchu). The non-dorsal fin goldfish would have originated from the dorsal fin goldfish [5].

The traditional biology of the goldfish has been widely studied [6] [7]. However, its genetic analysis has been rarely investigated [8]-[10]. Owing to its richness in strains with characteristic color and morphology, it is of importance to investigate the population structure and genetic relationship of this species for better understanding of the historical and current forces shaping its morphological characteristics. Furthermore, by now, only 5 microsatellite markers have been developed for C. auratus [11], relatively low locus numbers and polymorphism limits its application in the population genetic evaluation of this species. Meanwhile, more polymorphic novel microsatellite markers are extremely needed for investigation of the population structure and strain evaluation of goldfish.

Nowadays, the goldfish with sarcoma have increasingly tended to be more expensive than other goldfish [2] [12]-[14], more strains will be developed in this taxonomy. However, the genetic relationship and structure have not been investigated among the strains of goldfish with sarcoma. It is necessary to investigate genetic analysis of this taxonomy of goldfish for better conducting breeding program and developing ornamental strain in goldfish. In this paper, we conducted the genetic investigation of six representative populations of sarcoma goldfish by means of ten novel microsatellite markers which were newly developed. The objective of current study was to firstly understand the genetic structure and differentiation among these populations and to evaluate the utility of newly novel microsatellite markers.

\section{Materials and Methods}

\subsection{Samples Collection}

A total of 243 individuals were collected from six populations of goldfish with sarcoma, which were from Shanghai Nanhui fish farm in China. According to the classification of the goldfish variation [15], they included lionhead, tigerhead and oranda. These six representative populations were red tigerhead (RT), white tigerhead (WT), red lionhead (RL) and black lionhead (BL), white oranda with red cap (RC) and white oranda with yellow cap (YC), respectively. The sample information is listed in Table 1. A small piece of the caudal fin was excised from each specimen and stored in $95 \%$ ethanol.

\subsection{DNA Extraction and SSR Methods}

Genomic DNA was extracted from a small piece of the caudal fins using standard phenol-chloroform method [16]. The goldfish (C. auratus) microsatellite was produced through the enrichment by magnetic beads [17]. A total of 56 pairs of primers could successfully amplify the products, but only 18 (32.1\%) were polymorphic in the tested specimens. From deposited in GenBank, these 18 microsatellites were Accession No. GU181334GU181348. And all the 18 loci did not deviate from the Hardy-Weinberg equilibrium (HWE). The results de-

Table 1. Summary statistics of genetic parameters in the six populations of goldfish.

\begin{tabular}{ccccccc}
\hline & $F_{\mathrm{N}}$ & $N$ & $A_{\mathrm{R}}$ & $H_{\mathrm{O}}$ & $H_{\mathrm{E}}$ & $F_{\mathrm{IS}}$ \\
\hline RT & Red Tigerhead & 42 & 3.0217 & 0.5381 & 0.4470 & -0.2068 \\
WT & White Tigerhead & 42 & 2.7474 & 0.3571 & 0.3262 & -0.0956 \\
RL & Red Lionhead & 42 & 2.9777 & 0.6262 & 0.5374 & -0.1675 \\
BL & Black Lionhead & 42 & 2.8824 & 0.4476 & 0.4366 & -0.0256 \\
RC & White Oranda with Red Cap & 42 & 3.5628 & 0.7381 & 0.5950 & -0.2441 \\
YC & White Oranda with Yellow Cap & 33 & 3.1000 & 0.6818 & 0.5263 & -0.3014 \\
\hline
\end{tabular}

$F_{\mathrm{N}}$, full name; $N$, numbers of specimens; $A_{\mathrm{R}}$, mean allelic richness; $H_{\mathrm{O}}$, mean observed heterozygosity overall loci; $H_{\mathrm{E}}$, mean expected heterozygosity overall loci; $F_{\text {IS }}$, inbreeding coefficients. 
monstrate that these 18 microsatellite loci might be useful for the assessment of genetic variation and population structure in goldfish.

\subsection{Microsatellite Amplification}

A total of 10 polymorphic microsatellite loci (Table 2) those we chose from the 18 loci newly developed by our laboratory were used to perform polymerase chain reactions (PCRs). The reaction mixture was $10 \mu \mathrm{L}$ containing $1 \mu \mathrm{L}$ genomic DNA $(20 \mathrm{ng} / \mu \mathrm{L}), 5 \mu \mathrm{L}$ buffer, $0.2 \mu \mathrm{M}$ dNTPs, $1.5 \mu \mathrm{M} \mathrm{MgCl}_{2}, 0.5 \mu \mathrm{M}$ Taq DNA polymerase (Tiangen, China), $1 \mu \mathrm{L}$ primers $(0.5 \mu \mathrm{M}$ each), and $3 \mu \mathrm{L}$ distilled water. The PCR reactions were conducted in an Eppendorf thermocycler (Eppendorf, Germany) under the following conditions: initial denaturation for 5 min at $94^{\circ} \mathrm{C}$; followed by 35 cycles for $30 \mathrm{~s}$ at $94^{\circ} \mathrm{C}, 30 \mathrm{~s}$ at optimal annealing temperature (Table 2), and $30 \mathrm{~s}$ at $72^{\circ} \mathrm{C}$, final extension for $10 \mathrm{~min}$ at $72^{\circ} \mathrm{C}$. The PCR products were electrophoresed in $8 \%$ polyacrylamide gel and the fragment sizes (bp) were recorded by Gel-PRO ANALYZER (Media Cyberbetics, USA) using PBR322 as a ladder marker.

\subsection{Data Analysis}

Genetic diversity of the six populations was estimated as allelic richness $\left(A_{\mathrm{R}}\right)$, observed $\left(H_{\mathrm{O}}\right)$ and expected $\left(H_{\mathrm{E}}\right)$ heterozygosity, and inbreeding coefficient $\left(F_{\text {IS }}\right)$ using FSTAT version 2.9.3.2 [18] [19]. Departure from HardyWeinberg equilibrium (HWE) was tested between populations and calculated using POPGENE3.2 [20]. Genetic variability within and among populations were estimated using analysis of molecular variance (AMOVA) and comparisons of pairwise $F_{\mathrm{ST}}$ between populations were conducted using ARLEQUIN 3.5 [19] [21] with 1000 permutations.

Furthermore, two methods were used to further reveal population differentiation in the studied samples. First, a principal components analysis (PCA) was performed using GENALEX version 6.1 [22] to reveal the internal population structure and to visualize population discreteness. Second, Bayesian clustering analysis implemented with STRUCTURE 2.2 [23] was performed to estimate the most likely number of genetic clusters $(K)$ of populations and assign individuals to those clusters without using prior information about their sample origin. The admixture model was employed with 20,000 burn-in periods and 1,000,000 Markov Chain Monte Carlo (MCMC) iterations. To identify the most probable posterior probability $K$ value, the simulation program was running with increasing numbers of clusters $(K)$ from two to four, with a plateau used to indicate the most likely $K$ [19] [24]. For each successive value of genetic clusters $(K)$, the inferred clusters were analyzed and visualized as colored box plots using the DISTRUCT program [25].

Table 2. Sequences, annealing temperature of PCR amplification and size of detected alleles for the ten microsatellite markers in Carassius auratus.

\begin{tabular}{|c|c|c|c|c|c|}
\hline Loci & Primer Sequences (5’-3’) & Repeat Motif & $\mathrm{Ta}\left({ }^{\circ} \mathrm{C}\right)$ & Allele Range & GenBank Accession No. \\
\hline G003 & $\begin{array}{l}\text { F: AACATGATACCTGAGGGAGGG } \\
\text { R: TGCATCACAGGAACGTGTTG }\end{array}$ & $(\mathrm{AC})_{12} \mathrm{C}(\mathrm{CA})_{7}$ & 56.1 & $186-198$ & GU181334 \\
\hline G006 & $\begin{array}{l}\text { F: AAACACAGTGGCAGGAAGAC } \\
\text { R: CAGTCGAAGCTGCAGATGTT }\end{array}$ & $(\mathrm{CA})_{14}$ & 56.1 & $119-170$ & GU181335 \\
\hline G012 & $\begin{array}{l}\text { F: CACACCCCTGTAGACTGTTGA } \\
\text { R: GCAGGATTTCGTAGACAAAGA }\end{array}$ & $(\mathrm{TG})_{43}$ & 60.8 & $305-340$ & GU181337 \\
\hline G016 & $\begin{array}{l}\text { F: TGGTCACCTGTGACTTCATC } \\
\text { R: CACAACTCAAACTGGCTACAG }\end{array}$ & $(\mathrm{AC})_{15}$ & 54.8 & $148-172$ & GU181338 \\
\hline G017 & $\begin{array}{l}\text { F: GTGCAGCAGTTCCAGTTTCT } \\
\text { R: CTGTGTGCCCCACTGATATT }\end{array}$ & $(\mathrm{CA})_{11}$ & 56.1 & $238-270$ & GU181338 \\
\hline G021 & $\begin{array}{l}\text { F: GCTTTAGACACCTTGCCAGA } \\
\text { R: TGCCAGACGAGTTTGTCTAC }\end{array}$ & $(\mathrm{TG})_{12}$ & 53 & $145-165$ & GU181339 \\
\hline G022 & $\begin{array}{l}\text { F: TGTGTAGCACGTAGAGGAATG } \\
\text { R: AGACAGACTGGACCAAATGC }\end{array}$ & $(\mathrm{GTGC})_{5}(\mathrm{GT})_{11}$ & 57.6 & $125-180$ & GU181340 \\
\hline G030 & $\begin{array}{l}\text { F: CAGTGCTGGTTAGCAAATGC } \\
\text { R: CGCAGTGGTTGTGATTCTGT }\end{array}$ & $(\mathrm{GT})_{18}$ & 58.8 & $160-201$ & GU181341 \\
\hline G043 & $\begin{array}{l}\text { F: TGCTGCTCGAACCATCAT } \\
\text { R: TGAGTGTGATTAGCAGACCG }\end{array}$ & $(\mathrm{AC})_{13}$ & 58.7 & $165-200$ & GU181344 \\
\hline G048 & $\begin{array}{l}\text { F: GGAACTCTGTCTGATTGGAC } \\
\text { R: TCCTGCACACTCTTACACAC }\end{array}$ & $(\mathrm{GT})_{13}$ & 56.1 & $165-199$ & GU181347 \\
\hline
\end{tabular}

F: forward primers; R: reverse primers. 
The genetic bottleneck about the six populations of goldfish with sarcoma was detected by using the software of Bottleneck 1.202. It was analyzed through two methods, the first one is to use stepwise mutation model (SMM) and two-phased mutation model (TPM) [26] [27], as the evolutional mutation model of most microsatellite loci comes closer to SMM model, not IAM model. The examining parameters are as follows: the square deviation of TPM is $10 \%$, the number of SMM/TPM is $90 \%, 95 \%$ and $98 \%$, respectively. The repeat number is 10,000 . Statistical significance was tested by Wilcoxon signed-rank test. The second is model-drift indicator, for example, the population without suffering bottlenecked revealed the normal L-model distribution, which is near to mutation-drift equilibrium. Otherwise, the bottlenecked population revealed a drift model [19] [28].

\section{Results}

\subsection{Genetic Variations within Populations}

A total of 243 alleles were observed for all samples based on 10 loci used (Table 2). The RC had the highest allelic richness $\left(A_{R}\right)$ and expected heterozygosity $\left(H_{\mathrm{E}}\right)$, observed heterozygosity $\left(H_{\mathrm{O}}\right)$. The WT had the lowest allelic richness $\left(A_{\mathrm{R}}\right)$, as well as observed heterozygosity $\left(H_{\mathrm{O}}\right)$, expected heterozygosity $\left(H_{\mathrm{E}}\right)$. Interestingly, all $F_{\mathrm{IS}}$ values from the six populations were significantly negative.

\subsection{Genetic Differentiation and Relationship among Populations}

The results of AMOVA revealed about $98.65 \%$ genetic variation contributed to differences within individuals, and only $16.35 \%$ contributed to differences among populations (Table 3), but there are extremely significant differences among the six populations $(P<0.001)$. Furthermore, there were the highest level of differences $\left(F_{\mathrm{CT}}\right.$ $=0.1891, P=0.0186$ ) when six populations were classified into three groups ((1) RT, WT; (2) RL, BL, YC; (3) $\mathrm{RC})$.

The pairwise $F_{\mathrm{ST}}$ values between populations are presented in Table 4. All pairwise $F_{\mathrm{ST}}$ values, ranging from 0.0120 to 0.3045 , were significant $(P<0.01)$. Moreover, the WT population had higher $F_{\mathrm{ST}}$ value comparing to the others except RT. The result indicated that there is higher genetic differentiation between the WT and the other four populations. And the lowest genetic differentiation was found between WT and RT.

Relationships among populations were further illustrated by the two-dimensional scatter plot of a PCA based on the squared Euclidean (Figure 1). Both RT and WT which were closer to each other owned no any connection with the other four populations. Meanwhile, there was some connection among the populations RL, BL, YC and RC. Moreover, there was obvious genetic differentiation between RC and the other five populations. There was the closest genetic relationship among the YC, RL and BL population.

The genetic relationship of the six populations was analyzed by Structure 2.3.2, the result indicated that three clusters (RT, WT; RL, BL, YC; RC) were clearly identified (Figure 2). The genetic difference of WT population was closer to RT and their genetic difference were both far away from the other four populations. There were the nearest genetic difference among YC, RL and BL population of goldfish. The results are similar to the

Table 3. Analysis of molecular variance (AMOVA) for the six populations of goldfish.

\begin{tabular}{|c|c|c|c|c|}
\hline Source of variation & D.f. & $\begin{array}{c}\text { Percentage of } \\
\text { variation }\end{array}$ & $\begin{array}{l}\text { Fixation } \\
\text { indices }\end{array}$ & $P$ value \\
\hline \multicolumn{5}{|c|}{ One group: (RT, WT, RL, BL, RC, YC) } \\
\hline Among populations & 5 & 16.35 & $F_{I S}=-0.1794$ & $=1.000$ \\
\hline Among individuals within populations & 237 & -15.00 & $F_{S T}=0.1635$ & $<0.001$ \\
\hline Within individuals & 243 & 98.65 & $F_{I T}=0.0135$ & $=0.8220$ \\
\hline \multicolumn{5}{|c|}{ Three groups: (RT, WT; RL, BL, YC; RC) } \\
\hline Among groups & 2 & 18.91 & $F_{C T}=0.1891$ & $=0.0186$ \\
\hline Among populations within groups & 3 & 2.73 & $F_{S C}=0.0336$ & $<0.001$ \\
\hline Among individuals within populations & 237 & -13.51 & $F_{I S}=-0.1724$ & $=1.000$ \\
\hline Within individuals & 243 & 91.87 & $F_{I T}=0.0813$ & $=0.3979$ \\
\hline
\end{tabular}


Table 4. Pairwise population differentiation FST values between the six populations of goldfish based on 10 microsatellite loci (SSR).

\begin{tabular}{|c|c|c|c|c|c|c|}
\hline Populations & $\mathrm{RT}$ & WT & $\mathrm{RL}$ & BL & $\mathrm{RC}$ & YC \\
\hline WL & $0.0299^{* * *}$ & & & & & \\
\hline RT & $0.1759^{* *}$ & $0.2628^{* *}$ & & & & \\
\hline BT & $0.2253^{* *}$ & $0.3045^{* *}$ & $0.0214^{* *}$ & & & \\
\hline $\mathrm{RC}$ & $0.1775^{* *}$ & $0.2750^{* *}$ & $0.0739^{* *}$ & $0.1412^{* *}$ & & \\
\hline YC & $0.1830^{* *}$ & $0.2795^{* *}$ & $0.0120^{* *}$ & $0.0695^{* *}$ & $0.0841^{* *}$ & \\
\hline
\end{tabular}

${ }^{* *} P<0.01 ;{ }^{*} P<0.05$; NS, no significance $(P>0.05)$.

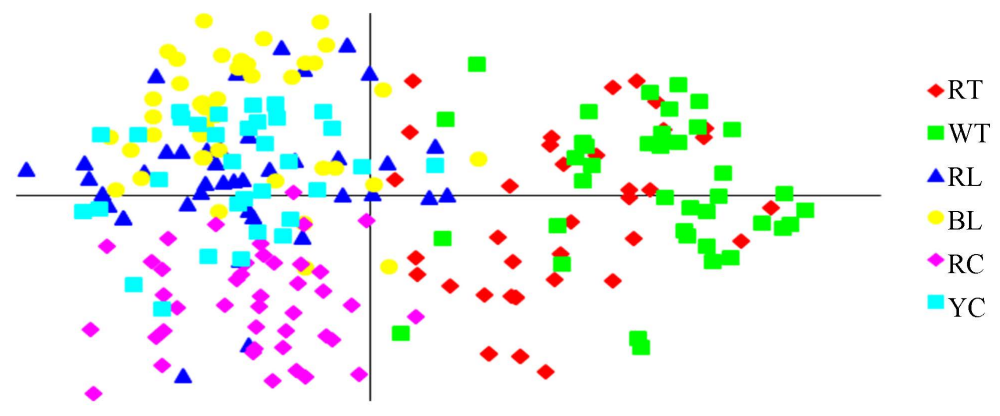

Figure 1. Principal coordinate analysis (PCA) of allele frequencies at ten microsatellite loci. Note: The letters of the represent scattered grams based on the squared Euclidean genetic distance matrix.

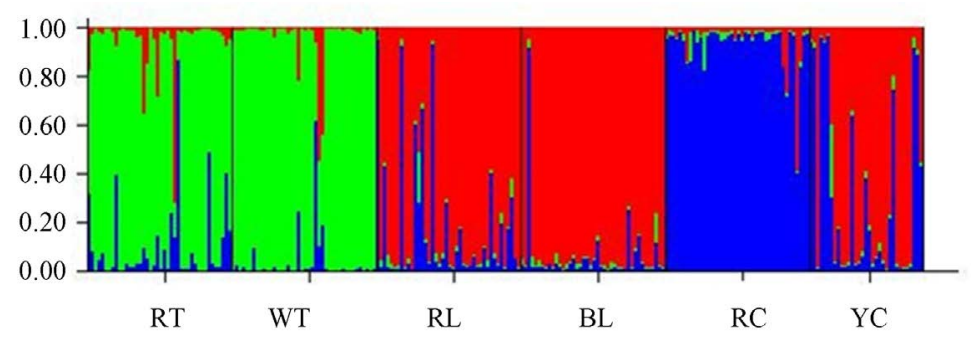

Figure 2. Population structure differences of the six populations of goldfish based on ten microsatellite loci using Bayesian clustering analysis ( $\mathrm{K}=3$ ).

one of PCA analysis.

\subsection{The Test of Genetic Bottleneck}

The genetic bottleneck about the six populations of goldfish with sarcoma was detected by using the software of Bottleneck 1.202 (Table 5). According to the TPM and SMM models, there were significant genetic bottleneck in the populations of RL, RC and YC, and no significant bottleneck signals in the population of RT, WT and BL. Similarly, the distribution of the allele frequencies also showed the results as the TPM and SMM models.

\section{Discussion}

Genetic variation is non-randomly distributed among populations, species and higher taxa [19] [29]. This distribution of alleles and genotypes in space or in time is often referred to the genetic structure of a population [30]. In the present study, the observed heterozygosities were between 0.3571 and 0.7381 , while expected heterozygosities were between 0.3262 and 0.5950 , demonstrating that the six goldfish populations detected by the 10 
Table 5. $P$-values of bottleneck tests for the six populations of goldfish using two phased mutation model (TPM), stepwise mutation model (SMM) and mode shift indicator.

\begin{tabular}{|c|c|c|c|c|c|}
\hline \multirow{2}{*}{ Population } & \multicolumn{4}{|c|}{ Heterozygosity Excess ( $P$ Values) } & \multirow{2}{*}{ Mode-Shift } \\
\hline & ТРМ (90\%) & ТРМ (95\%) & ТРМ (98\%) & SMM & \\
\hline $\mathrm{RT}$ & 0.5566 & 0.8457 & 0.8457 & 0.8457 & Normal \\
\hline WT & 0.2754 & 0.2754 & 0.2324 & 0.1309 & Normal \\
\hline RL & $0.0020^{* *}$ & $0.0029^{* *}$ & $0.0049^{* *}$ & $0.0049^{* *}$ & Shifted \\
\hline $\mathrm{BL}$ & 0.1602 & 0.4922 & 0.4922 & 0.4316 & Shifted \\
\hline $\mathrm{RC}$ & $0.0049^{* *}$ & $0.0098^{* *}$ & $0.0137^{*}$ & $0.0186^{*}$ & Normal \\
\hline YC & $0.0098^{* *}$ & $0.0098^{* *}$ & $0.0322^{*}$ & $0.0322^{*}$ & Shifted \\
\hline
\end{tabular}

microsatellite primers had relatively high observed and expected heterozygosities. They have the capacity of farther breeding selection [31] [32]. At the same time, they will own relative high evolutional capacity and stronger adaptive capacity to the environmental conditions as well as the dominant capacity on their growth and disease resistance [33] [34]. The results seemed to indicate the genetic diversity of WT was obvious lower than other five populations. Meanwhile, WT population might have been experienced a founder effect during the later development [35].

AMOVA revealed about $98.65 \%$ genetic variation contributed to differences within individuals, and only $16.35 \%$ contributed to differences among populations. There are extremely significant differences among the six populations $(P<0.001)$, while there were obvious significant differences $\left(F_{\mathrm{CT}}=0.1891, P=0.0186\right)$ among goldfish varieties classified into three groups (RT, WT; RL, BL, YC; RC). It may be owned to the lack communication among the populations. According to the $F_{\mathrm{ST}}$ value comparing, the result indicated that there is higher genetic differentiation between WT and other four populations, while there is lowest genetic differentiation between WT and RT $\left(F_{\mathrm{ST}}=0.0299\right)$. And there may be the outcrossing within the six populations [36]. The phenomenon might be due to mankind's activity which affected the genetic differentiation within goldfish populations. As an important ornamental fish with numerous varieties, inevitably they will be often interference with mankind's activity. There was the study indicating that the mankind's activity could affect the genetic diversity and differentiation [37]-[39]. Relationships among populations were further illustrated by the two-dimensional scatter plot of a PCA based on the squared Euclidean. It showed that there was obvious genetic diversity between RC and other five populations. The result can provide reference basis for the fine variety breeding of goldfish. In accordance with taxonomy system, RC and YC populations are belong to the fish just with head growth on the top of the head, RT and WT population are belong to the fish with the head growth extending to the opercula and even covering the eyes, while RL and BL population are belong to the fish without dorsal fin, short and egg-shaped body, meanwhile, they have the head growth extending to the opercula and even the eyes [15] [40]. According to the analysis by PCA and STRUCTURE analysis, it indicated that there was an obvious genetic difference between RC and other five populations. The genetic difference of WT population was closer to RT population. And their genetic differences were both far away from other four populations. There were the nearest genetic difference among YC, RL and BL population of goldfish. Their analysis results are in accordance with the one analyzed by AMOVA. The results can show that there's no obvious relationship between the genetic differentiation within populations and the varieties those including sarcoma. And this is different from the traditional taxonomy system. Therefore, as a scientific researcher on goldfish, we can devote ourselves to study what is the real cause of the goldfish classified in terms of genetics. And we even will clearly know which gene can control their color difference of goldfish sarcoma.

Due to the changing of living environment and the artificial selection, the differentiation of goldfish genotype tended to be changed during gene diosmosis development. Especially, as an ornamental fish, their commercial activity often takes place. The numbers of WT, RT and BL populations might actively be recovered what had been lost. And all we know that the breeders like to pay attention to the goldfish variation and hope to develop the goldfish owning high ornamental value by keeping their variation forever, which might be the most important reason to get the active population gene. 
In the present study, the average observed heterozygosity was higher than expected heterozygosity among the six populations, showing that the excess heterozygote generally existed within the population. This phenomenon often appears in the study materials which has relative less or close population. For example, filial generation population in the breeding one was produced from limited parents, the founder and bottleneck effect can lead to the phenomenon of linkage disequilibrium [41]. This might be related to that the most goldfish varieties are cultured population at the present day. At the present time, RC belongs to the most typical and stable goldfish variety in the goldfish with different head characteristics [42]. Egg-fish goldfish appearing gets a leap for all centuries. Theoretically speaking, the goldfish deviated farther from their original species and they will get the higher evolution. In a sense, the lack of dorsal fin is positive to the evolution process. Whether to regain the goldfish species or to improve their varieties, we still need a long-hard exploration and research to finish.

\section{Acknowledgements}

This work was funded by the Key Project of Developing Agriculture through Science and Technology of Shanghai Municipal Agricultural Commission Shanghai, Shanghai University Knowledge Service Platform-Shanghai Ocean University Aquatic Animal Breeding Center (ZF1206) and the Shanghai Leading Academic Discipline Project (Grant No. Y1101).

\section{References}

[1] Liu, J.C. and Chen, Z. (2008) The Culture of Chinese Goldfish. SDX Joint Publishing Company, Beijing, 1-3.

[2] Smartt, J. (2001) Goldfish Varieties and Genetics: Handbook for Breeders. Blackwell Science, Oxford, 80-93.

[3] Ning, L.L., Liang, J., Qiao, Y., Zhou, P.R. and Li, J.Z. (2006) The Sequence Feature of Mitochondrial DNA Control Region of Dragon-Eye Goldfishes and Oval Goldfishes. Life Science Research, 10, 119-124.

[4] Wang, C.Y. (2009) Goldfish Has Great Variation. Aquarium, 1, 26-32.

[5] Komiyama, T., Kobayashi, H., Tateno, Y., Inoko, H., Gojobori, T. and Ikeo, K. (2009) An Evolutionary Origin and Selection Process of Goldfish. Gene, 430, 5-11. http://dx.doi.org/10.1016/j.gene.2008.10.019

[6] Liang, Q.J. and Peng, Y.X. (1994) An Analysis of the Muscle Protein of the Wild Crucian (Carassius auratus) and Five Representative Varieties of Goldfishes (C. auratus var.) by Electrophoresis Methods. Zoological Research, 15, 68-75.

[7] Liang, Q.J. and Peng, Y.X. (1998) An Exploration on the Antigenicity of the Serum of Several Strains of Goldfishes from China. Journal of Fisheries of China, 22, 16-21.

[8] Kajishima, T. (1977) Genetic and Developmental Analysis of Some New Color Mutants in the Goldfish, Carassius auratus. Genetics, 86, 161-174.

[9] Wang, X.M., Song, W.Q. and Li, X.L. (1998) Detection of the Genomic DNA Polymorphisms in the Wild Crucian and Four Representative Varieties of Goldfish Using PAPD Technique. Hereditas (Beijing), 20, 7-11.

[10] Mu, X.D., Bai, J.J., Wang, X.J., Ye, X., Hu, Y.C. and Luo, J.R. (2007) Genetic Diversity of Three Cultured Populations of Goldfish Revealed by RAPD Method. Marine Fisheries, 29, 20-24.

[11] Zheng, W., Stacey, N.E., Coffin, J. and Strobeck, C. (1995) Isolation and Characterization of Microsatellite Loci in the Goldfish Carassius auratus. Molecular Ecology, 4, 791-792. http://dx.doi.org/10.1111/j.1365-294X.1995.tb00282.x

[12] Matsui, Y. (1963) Goldfish. Hoikusha Publishing Co., Ltd., Osaka, 127-130.

[13] Kojima, Y. and Takai, A. (1995) The World of Fish. Shokabo Publishing Co., Ltd, Tokyo, 134-154.

[14] Suzuki, K. (1997) The Goldfish and Japanese. San-Ichi Publishing Co., Ltd., Tokyo. (In Japanese)

[15] Wang, H.Y. (2000) Atlas of Chinese Goldfish. China Culture Art Publishing House, Beijing, 2-6.

[16] Sambrook, J. and Russell, D.W. (2002) Molecular Cloning: A Laboratory Manual. 3rd Edition, Science Press, Beijing, 461-471.

[17] Cheng, Q.X., Wang, C.H., Xu, J.W., Wang, J. and Yang, Q.L. (2009) Novel Microsatellite Markers for Endangered Hepu Mitten Crab, Eriocheir hepuensis. Conservation Genetics Resources, 1, 357-360. http://dx.doi.org/10.1007/s12686-009-9082-z

[18] Goudet, J. (1995) FSTAT (Version 1.2): A Computer Program to Calculate F-Statistics. Journal of Heredity, 86, 485486.

[19] Luikart, G. and Cornuet, J.M. (1998) Empirical Evaluation of a Test for Identifying Recently Bottlenecked Populations from Allele Frequency Data. Conservation Biology, 12, 228-237.

[20] Yeh, F., Boyle, T., Rongcai, Y., Ye, Z. and Xian, J. (1999) POPGENE Version 1.32. 
http://www.ualberta.ca/ fyeh/popgene_download.html

[21] Excoffier, L. and Lischer, H.E.L. (2010) Arlequin Suite ver 3.5: A New Series of Programs to Perform Population Genetics Analyses under Linux and Windows. Molecular Ecology Resources, 10, 564-567. http://dx.doi.org/10.1111/j.1755-0998.2010.02847.x

[22] Peakall, R. and Smouse, P.E. (2006) GENALEX 6: Genetic Analysis in Excel. Population Genetic Software for Teaching and Research. Molecular Ecology Notes, 6, 288-295. http://dx.doi.org/10.1111/j.1471-8286.2005.01155.x

[23] Pritchard, J.K., Stephens, M. and Donnelly, P. (2000) Inference of Population Structure Using Multilocus Genotype Data. Genetics, 155, 945-959.

[24] Falush, D., Stephens, M. and Pritchard, J.K. (2003) Inference of Population Structure Using Multilocus Genotype Data: Linked Loci and Correlated Allele Frequencies. Genetics, 164, 1567-1587.

[25] Rosenberg, N. (2004) DISTRUCT: A Program for the Graphical Display of Population Structure. Molecular Ecology Notes, 4, 137-138. http://dx.doi.org/10.1046/j.1471-8286.2003.00566.x

[26] Rienzo, A.D., Peterson, A.C., Garza, J.C., Valdes, A.M., Slatkin, M. and Freimer, N.B. (1994) Mutational Processes of Simple-Sequence Repeat Loci in Human Populations. Proceedings of the National Academy of Sciences of the United States of America, 91, 3166-3170. http://dx.doi.org/10.1073/pnas.91.8.3166

[27] Cornuet, J.M. and Luikart, G. (1996) Description and Power Analysis of Two Tests for Detecting Recent Population Bottlenecks from Allele Frequency Data. Genetics, 144, 2001-2014.

[28] Luikart, G., Sherwin, W.B., Steele, B.M. and Allendorf, F.W. (1998) Usefulness of Molecular Markers for Detecting Population Bottlenecks via Monitoring Genetic Change. Molecular Ecology, 7, 963-974. http://dx.doi.org/10.1046/j.1365-294x.1998.00414.x

[29] Nevo, E. (1998) Genetic Diversity in Wild Cereals: Regional and Local Studies and Their Bearing on Conservation $e x$ Situ and in Situ. Genetic Resources and Crop Evolution, 45, 355-370. http://dx.doi.org/10.1023/A:1008689304103

[30] Loveless, M.D. and Hamrick, J.L. (1984) Ecological Determinants of Genetic Structure in Plant Populations. Annual Review of Ecology and Systematics, 15, 65-95. http://dx.doi.org/10.1146/annurev.es.15.110184.000433

[31] Ott, T. (2001) Analysis of Human Genetic Linkage. Revised Edition, Johns Hopkins University Press, Baltimore.

[32] Zhao, M.Z., Li, Q., Qin, Q., Cai, Y.X., Xu, Z.Q., Wang, M.H., Chen, M.H., Chen, X.H., Ge, J.C. and Bian, W.J. (2011) Genetic Diversity Based on Microsatellite Markers in Five Channel Catfish (Ictalurus punctatus) Populations. Journal of Aquaculture, 32, 24-30.

[33] Beardmore, J.A., Mair, G.C. and Lewis, R.I. (1997) Biodiversity in Aquatic Systems in Relation to Aquaculture. Aquaculture Research, 28, 829-839.

[34] Ma, B., Jiang, Z.F. and Huo, T.B. (2009) Analysis of Genetic Variation and Geographic Divergence of Thymallus tugarinae by Microsatellite. Journal of Fishery Science of China, 16, 678-688.

[35] Zhang, Q., Ji, Y.J., Zeng, Z.G., Song, Y.L. and Zhang, D.X. (2007) Influence of the Founder Effect on Genetic Diversity of Translocated Populations: An Example from Hainan Eld's Deer. Chinese Journal of Zoology, 42, 54-60.

[36] Wright, S. (1978) Evolution and the Genetics of Populations, Volume. 4: Variability within and among Natural Population. University of Chicago Press, Chicago.

[37] Peggy, K., Daniel, J.P. and Heather, A.F. (1992) Spatial Genetic Structure in Two Tamarack [Larix laricina (Du ROI) K. Koch] Populations with Differing Establishment Histories. Evolution, 46, 572-576. http://dx.doi.org/10.2307/2409875

[38] Young, A.G. and Merriam, H.G. (1994) Effects of Forest Fragmentation on the Spatial Genetic Structure of Acer saccharum Marsh. (Sugar Maple) Populations. Heredity, 72, 201-208. http://dx.doi.org/10.1038/hdy.1994.27

[39] Aldrich, P.R., Hamrick, J.L., Chavarriaga, P. and Kochert, G. (1998) Microsatellite Analysis of Demographic Genetic Structure in Fragmented Populations of the Tropical Tree Symphonia globulifera. Molecular Ecology, 7, 933-944. http://dx.doi.org/10.1046/j.1365-294x.1998.00396.x

[40] Wang, C.Y (2007) Variation and Heredity of Goldfish. China Agricultural Press, Beijing.

[41] Innocentiis, S.D., Sola, L., Cataudella, S. and Bentzen, P. (2001) Allozyme and Microsatellite Loci Provide Discordant Estimates of Population Differentiation in the Endangered Dusky Grouper (Epinephelus marginatus) within the Mediterranean Sea. Molecular Ecology, 10, 2163-2175. http://dx.doi.org/10.1046/j.1365-294X.2001.01371.x

[42] Tian, S.X. (2009) Preliminary Exploration of the Egg-Fish Goldfish with Red Head. Aquarium, 1, 44-49. 
Scientific Research Publishing (SCIRP) is one of the largest Open Access journal publishers. It is currently publishing more than 200 open access, online, peer-reviewed journals covering a wide range of academic disciplines. SCIRP serves the worldwide academic communities and contributes to the progress and application of science with its publication.

Other selected journals from SCIRP are listed as below. Submit your manuscript to us via either submit@scirp.org or Online Submission Portal.
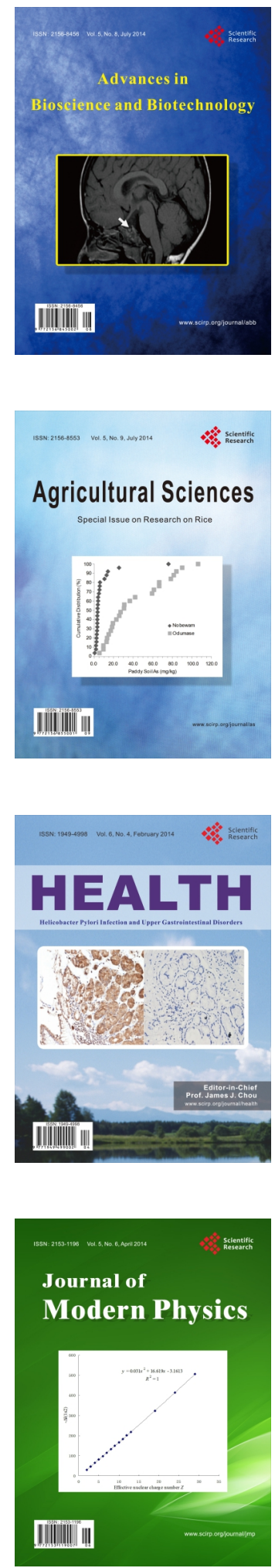
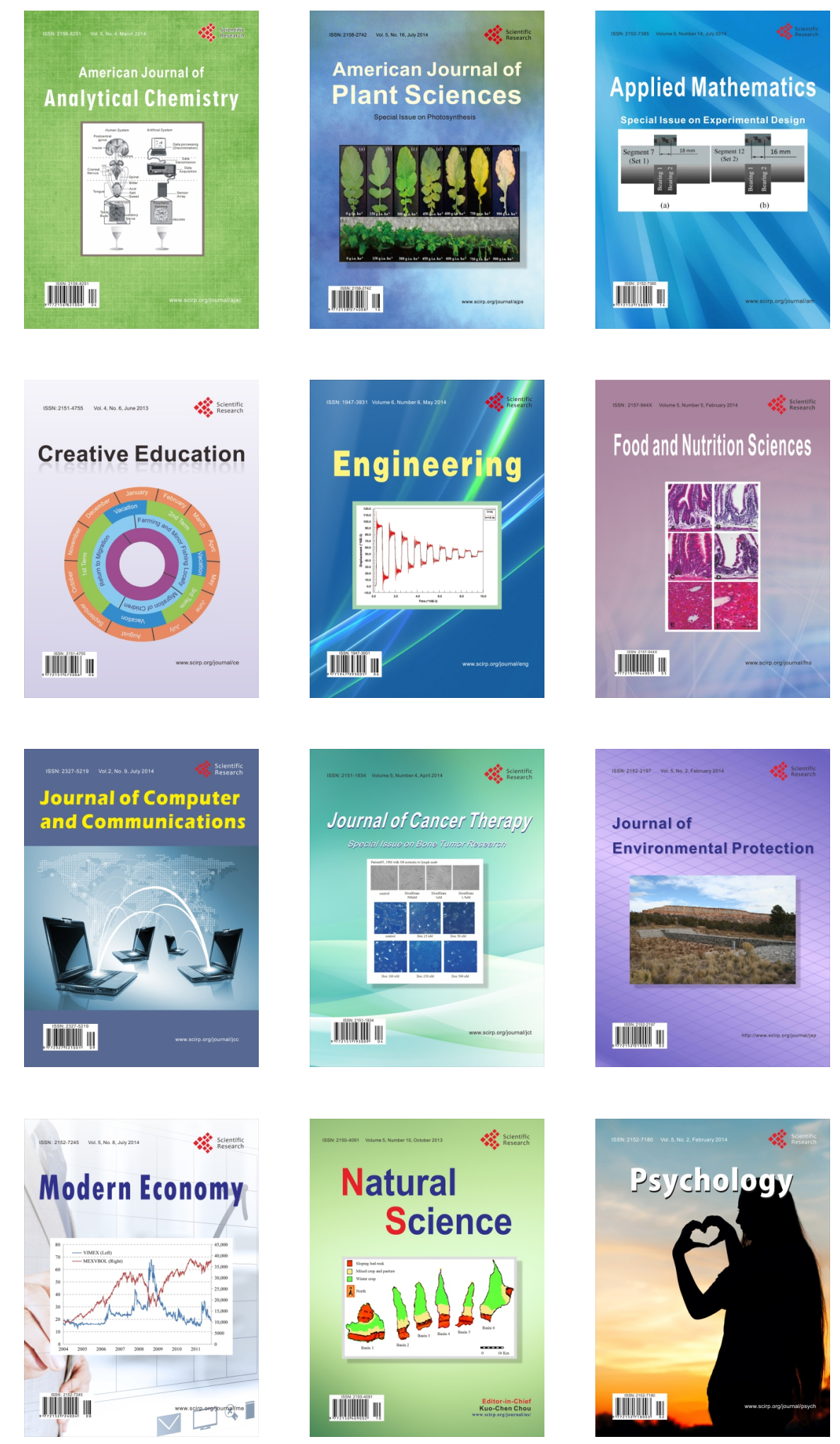